\title{
FREQUENCY OF ANENCEPHALY AND ITS ASSOCIATED ANOMALIES
}

\section{Shilpa K ${ }^{1}$, Priya Ranganath ${ }^{* 2}$, Sumathi $\mathrm{S}^{3}$.}

${ }^{1}$ Research Scholar, Department of Anatomy, BMCRI, Bangalore, Karnataka, India.

*2 Professor \& Head, Department of Anatomy, BMCRI, Bangalore, Karnataka, India.

${ }^{3}$ Assistant Professor, Department of Anatomy, BMCRI, Bangalore, Karnataka, India.

\section{ABSTRACT}

Introduction: Anencephaly accounts for one of the most common birth defects \& is associated with a high mortality \& morbidity. The objective was to determine frequency of anencephaly and its associated anomalies, risk factors, clinical presentations \& assess maternal awareness on folic acid supplementation and its preventive role in occurrence of anencephaly.

Materials and Methods: The study includes 60 anencephalic fetuses ( 23 males \& 37 females) of 20-30 weeks. The fetuses were examined for external abnormalities \& dissected. Measurements of crown heel, crown rump, head circumference, foot length, \& weight were taken. All the major organs were weighed \& data recorded. The samples were fixed with $10 \%$ buffered formaldehyde. The internal anomalies were noted.

Results: The number of deliveries was 57429 deliveries. 23(38.4\%) were males \& 37(61.6\%) were females. The frequency of anencephaly in 2014 was $15134 / 9(0.06 \%)$, in $201516361 / 21(0.13 \%)$. Weight of $40 \%$ were $<500 \mathrm{gms}$, $35 \%$ were between $500-1000 \mathrm{gms} \& 25 \%<1000$. Maternal age in $83.4 \%$ were $21-35$ years, in $<20$ years \& $>40$ years were $1.6 \%$ \& in $36-40$ years were $13.4 \%$. Associated anomalies were present in $42(70 \%)$ fetuses. Out of 42 fetuses, those who had associated anomalies were $17(40.4 \%)$ males and $25(59.6 \%)$ were females. All the fetuses had Acrania (100\%) \& $19(45.3 \%)$ fetuses had spina bifida; there were no anomalies found in reproductive system.

Conclusion: $4 \mathrm{mg}$ of folic acid should be taken before 6 months of conceiving \& during the entire pregnancy. In order to prevent the anencephaly and associated anomalies certain maternal risk factors should be avoided as prescribed by gynecologist.

KEY WORDS: Anencephaly, Crown Heel, Crown Rump, Head Circumference, Foot Length, Weight.

Address for Correspondence: Dr. Priya Ranganath, Professor \& Head, Department of Anatomy Bangalore Medical College \& Research Institute, Fort, Bangalore - 560002, Karnataka, India.

E-Mail: priya_ranganath@rediffmail.com

Access this Article online

Quick Response code

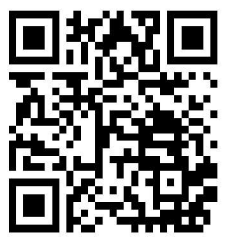

DOI: $10.16965 /$ ijar.2018.190

Journal Information

International Journal of Anatomy and Research

ICV for 2016 ISSN (E) 2321-4287 | ISSN (P) 2321-8967

90.30 https://www.ijmhr.org/ijar.htm

DOI-Prefix: https://dx.doi.org/10.16965/ijar

\section{Article Information}

Received: 16 Mar 2018

Peer Review: 18 Mar 2018

Revised: None
Accepted: 08 May 2018

Published (O): 05 Jun2018

Published (P): 05 Jun 2018

\section{INTRODUCTION}

Anencephaly is an embryological malformation of central nervous system; invariably lethal, characterized by the absence of brain $\&$ cranial chambers \& other defect of the cranial structure. Till now no treatment is available for Anencephaly but can be diagnosed by ultrasound scanning [1]. The neural defects are generally distinguished through the failure of neural tube to close during the early stage development of embryonic development [2]. It is a very rare congenital disorder in which malformation of brain occur during embryonic development at third post-fertilization week $\&$ characterized by a hyper-retroflexion of cephalic pole \& may lead to spontaneous abortion, stillbirth \& death in 
early infancy or lifetime disability [3,4]. Much of the brain is underdeveloped or absent altogether. Typically, the brainstem \& portion of midbrain is present; the portion of brain that is present controls only basic breathing, cardiovascular, suckling \& elimination reflexes; therefore the infants never gain consciousness or feel pain [5]. This study was designed to estimate frequency of anencephaly $\&$ its associated anomalies of fetal autopsies in Victoria Hospital and Vani Vilas Hospital, Bangalore, Karnataka, India.

\section{MATERIALS AND METHODS}

The present study of congenital anomalies in anencephalic fetuses was done at Bangalore Medical College \& Research Institute, Bangalore. Study was conducted over a time period of 3 years from August 2014 to June 2017. The total number of deliveries during this period was 57429. Of these deliveries the number of Fetuses with Anencephaly was 60 (23 males \& 37 females); the age of fetuses were 20 to 30 weeks. Consent for autopsy was requested compassionately, respectfully \& fully informed. The dissecting instruments required for fetal autopsy are small scissors \& forceps \& scalpels. Measurements of crown heel, crown rump, head circumference, foot length, \& weight are taken for comparison with standard chart. Dissection was performed by positioning of the body. The body was kept in supine position with a wooden block under the shoulder to keep the neck in extended position.

A curved incision was made bilaterally from the acromion process through the medial border of shoulder joint to mid-axillary line laterally, this continued to the iliac crest over the inguinal ligament to meet pubic symphysis. The skin with the superficial tissue flap was reflected up the root of the neck, then to the inferior margin of mandible bilaterally, taking care not to injure the neck structures and rectus sheath. This way, whole of the front of the neck, chest and abdomen was exposed [6].

Opening the abdominal cavity: A paramedian incision was made on rectus, near pubic symphysis, up to xiphoid process.

Opening thoracic cavity: Sternum was removed by cutting at costochondral junction and then separating sternoclavicular joint. All the major organs (lungs, heart, spleen, kidney, adrenal gland) were weighed \& data recorded in autopsy protocol along with expected values. Photographs were taken. The samples were fixed with $10 \%$ buffered formaldehyde approximately to 24 hours. All the procedures were approved by research board \& ethical committee of BMCRI, Bangalore. The associated abnormalities were grouped according to main organ system to which they belonged. The observed data were subjected to Fisher's exact tests and the significance was determined with $\mathrm{P}<0.05$ for statistical significance. The statistical tests were performed using software SPSS 15 (Statistical Package for Social Sciences)

\section{RESULTS}

The analysis of data revealed that incidence of anencephaly in Victoria and Vani Vilas hospital was 1.04 in 1000 births, over a period of 3 years from August 2014 to June 2017. The total number of deliveries during this period was 57429 deliveries. In the present study $23(38.4 \%)$ were males \& $37(61.6 \%)$ were females. The majority were females in the present study. The frequency of anencephaly in 2014 was 15134/9 $(0.06 \%)$ while in 2015 , it was $16361 / 21(0.13 \%)$ (Table 1).

Table 1: No of deliveries from August 2014 to June 2017.

\begin{tabular}{|c|c|c|c|}
\hline Year & $\begin{array}{c}\text { Number of } \\
\text { deliveries }\end{array}$ & Anencephaly & Percent \\
\hline Aug-Dec 2014 & 15134 & 9 & 0.06 \\
\hline Jan-Dec 2015 & 16361 & 21 & 0.13 \\
\hline Jan -Dec2016 & 17289 & 22 & 0.13 \\
\hline Jan -June 2017 & 8645 & 8 & 0.09 \\
\hline Total & 57429 & 60 & \\
\hline
\end{tabular}

Gestational age of fetuses was 20 to 30 weeks, in which 20 weeks was $26.6 \%$, 21weeks cases were $15 \%$ \& 30 weeks were $10 \%$ (Table 2).

Of total 60 fetuses the weight of $40 \%$ were $<500 \mathrm{gms}, 35 \%$ were between $500-1000 \mathrm{gms} \&$ $25 \%<1000$.

Classification of mothers according to age showed that maternal age in $83.4 \%$ were $21-35$ years, in $<20$ years $\&>40$ years were $1.6 \% \&$ in $36-40$ years were $13.4 \%$. The mean of maternal age is $24.4 \pm 4$.

When mothers were classified according to their 
level of education, it was noticed that $91.6 \%$ were found to be <high school (illiteracy), 5\% were high school \& > high school were $3.4 \%$. The study showed that majority of mothers were $76.7 \%$ unemployed (housewives) \& $46 \%$ of the respondents were found to have regular visits to antenatal care centers.

Associated anomalies were present in 42 (70\%) fetuses (Table 3). Out of 42 fetuses, those who had associated anomalies were 17 (40.4\%) males and 25 (59.6\%) were females. All the fetuses had Acrania (100\%) \& 19 (45.3\%) fetuses had spina bifida; there were no anomalies found in reproductive system.

Table 2: Age of fetuses.

\begin{tabular}{|c|c|c|}
\hline $\begin{array}{c}\text { Age of fetuses } \\
\text { (weeks) }\end{array}$ & $\begin{array}{c}\text { Frequency } \\
\text { of Age }\end{array}$ & Percent \\
\hline $\mathbf{2 0}$ & 16 & 26.6 \\
\hline $\mathbf{2 1}$ & 9 & 15 \\
\hline $\mathbf{2 2}$ & 6 & 10 \\
\hline $\mathbf{2 3}$ & 4 & 6.7 \\
\hline $\mathbf{2 4}$ & 7 & 11.6 \\
\hline $\mathbf{2 5}$ & 3 & 5 \\
\hline $\mathbf{2 6}$ & 1 & 1.6 \\
\hline $\mathbf{2 7}$ & 4 & 6.7 \\
\hline $\mathbf{2 8}$ & 1 & 1.6 \\
\hline $\mathbf{2 9}$ & 3 & 5 \\
\hline $\mathbf{3 0}$ & 6 & 10 \\
\hline Total & 60 & 100 \\
\hline
\end{tabular}

Table 3: Percentage distribution of associated anomalies $(n=42)$.

\begin{tabular}{|c|c|c|c|c|}
\hline \multirow{2}{*}{ System } & \multicolumn{4}{|c|}{ Anomalies Present } \\
\cline { 2 - 5 } & M & F & Total & $\begin{array}{c}\text { Percentage } \\
(\%)\end{array}$ \\
\hline Skull \& Face & 2 & 4 & 6 & 14.3 \\
\hline Vertebrae & 10 & 9 & 19 & 45.3 \\
\hline Limbs & 1 & 1 & 2 & 4.7 \\
\hline CVS & 1 & 0 & 1 & 2.3 \\
\hline Respiratory System & 0 & 4 & 4 & 9.5 \\
\hline GIT & 0 & 2 & 2 & 4.7 \\
\hline Urinary system & 1 & 1 & 2 & 4.7 \\
\hline Reproductive system & 0 & 0 & 0 & 0 \\
\hline Hernia & 2 & 0 & 2 & 4.7 \\
\hline Abdominal wall & 0 & 1 & 1 & 2.3 \\
\hline Other anomalies & 0 & 2 & 2 & 4.7 \\
\hline Total & 17 & 25 & 42 & 100 \\
\hline
\end{tabular}

M- Male, F-Female

Male fetuses had $40.4 \%$ of overall associated anomalies \& female fetuses $59.6 \%$ of associated anomalies. The female anencephalic fetuses were found to have more number of associated anomalies. (Chart 1)

Chart 1: Percentage of system wise Associated anomalies.

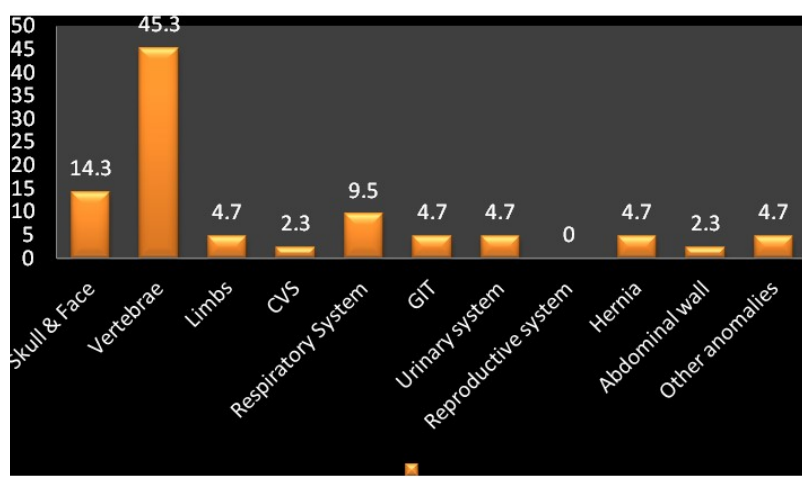

System wise anomalies: The 6 cases (14.3\%) had Facial defects (4.7\% were males \& 9.5\% were females). The most common defect was cleft palate \& cleft lip ( $9.5 \%$ cases), it was found to be statistically significant. In 19 (45.3\%) cases spina bifida was very common, in $1(2.3 \%)$ along with spina bifida cleft lip \& palate was also found. The spina bifida upto sacral region was seen in $4.7 \%$ of cases $\&$ it was found to be statistically significant (Table 4 ).

Table 4: Classification of spina bifida.

\begin{tabular}{|c|c|c|c|c|}
\hline Spinabifida & \multicolumn{3}{|c|}{ No of cases } & Percent \\
\hline & M & F & Total & \\
\hline Cervical & 2 & 3 & 5 & 11.9 \\
\hline Thoracolumbar & 5 & 1 & 6 & 14.3 \\
\hline Lumbosacral & 3 & 3 & 6 & 14.3 \\
\hline Sacral & 0 & $2 *$ & 2 & 4.7 \\
\hline
\end{tabular}

*statistically significant

Anomalies in limbs: 1 case (2.3\%) had Amelia of right lower limb, congenital dislocation of right elbow joint, malrotation of gut towards left, which was found to be statistically significant (Fig 1).

CVS: in 1 male fetus (2.3\%), there was a single ventricle (mono ventricle) on the left side, with two outlets (aorta \& pulmonary trunk), which was found to be statistically significant (Fig $2 a, b$ ).

Lungs: in 1 case (2.3\%), left lung had 2 fissures \& 3 lobes, in $1(2.3 \%)$ right lung had 3 fissures with 4 lobes. In 2 cases (4.7\%) both lungs had single oblique fissure with 2 lobes (Fig 3). In 1 case $(2.3 \%)$, there was malrotation of gut towards left side \& also absence of pancreas (Fig 4).

Urinary system: 1 case $(2.3 \%)$ had unilateral 
biureter on left side (Fig 5) \& 1 case (2.3\%) had horse shoe shaped kidney; both are statistically significant (Fig 6 a,b).

There were no anomalies found in reproductive system. In 2 male cases (4.7\%), there was umbilical hernia (Fig 7). Diaphragmatic hernia was not seen. Amniotic band syndrome (fig 8), encephalocele (fig 9) \& omphalocele (fig 10) were seen in $2.3 \%$ of cases.

Fig. 1: Amelia,cleft lip,umbilical hernia.

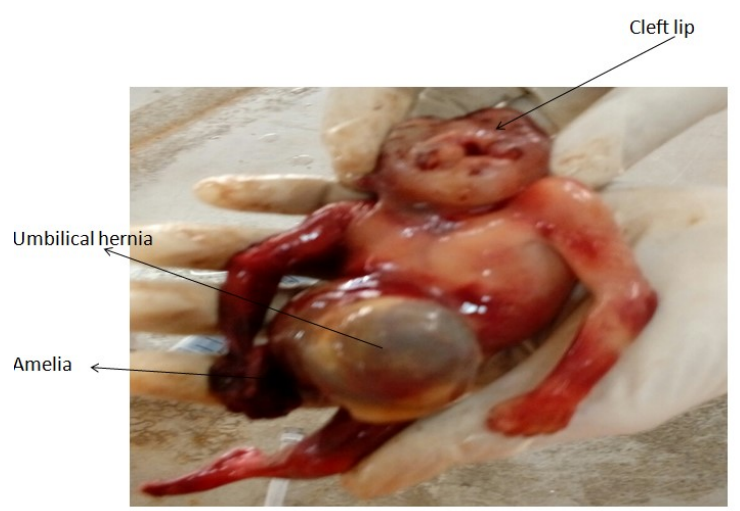

Fig. 2: double outlet, monoventricle.

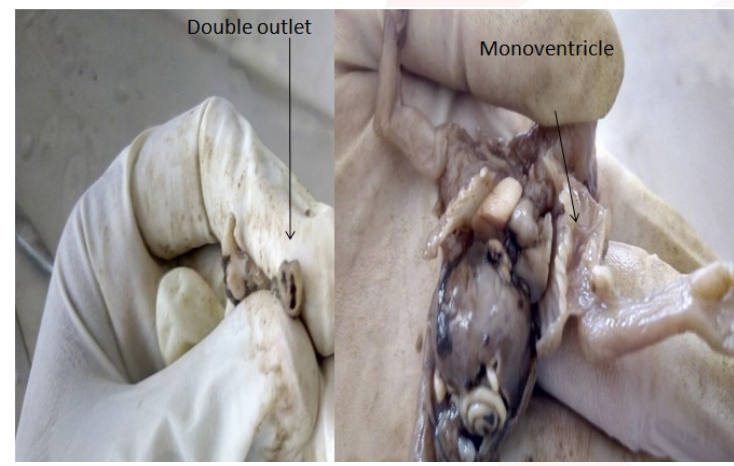

Fig. 3: bilobed right lung.

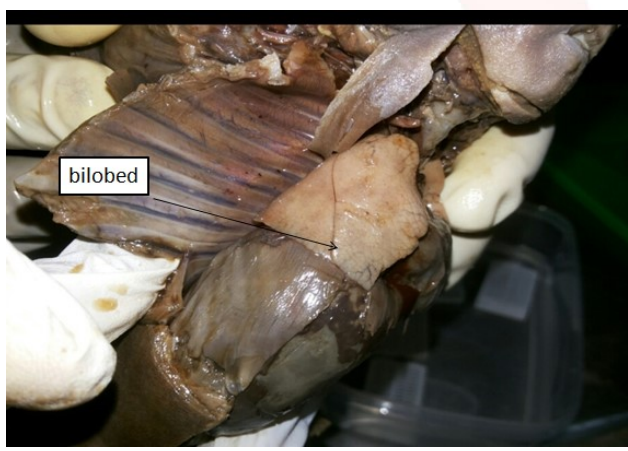

Fig. 4: absence of pancreas.

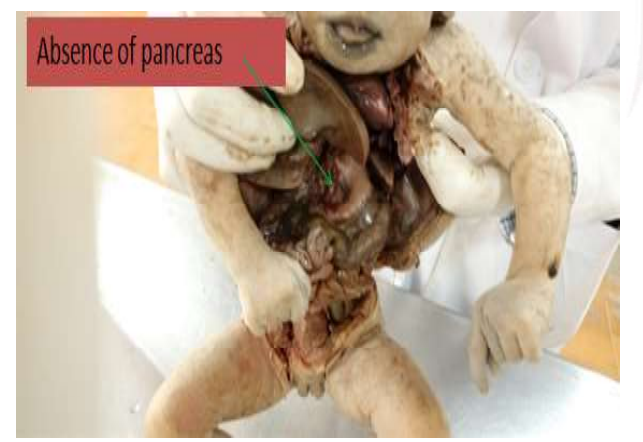

Fig. 5: biureter left side.

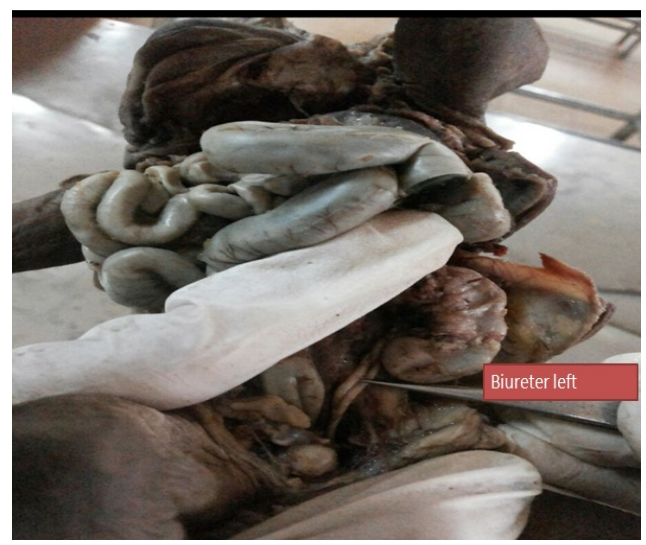

Fig. 6 a,b: Horse shoe shaped kidney.

Horse shoe shaped kidney

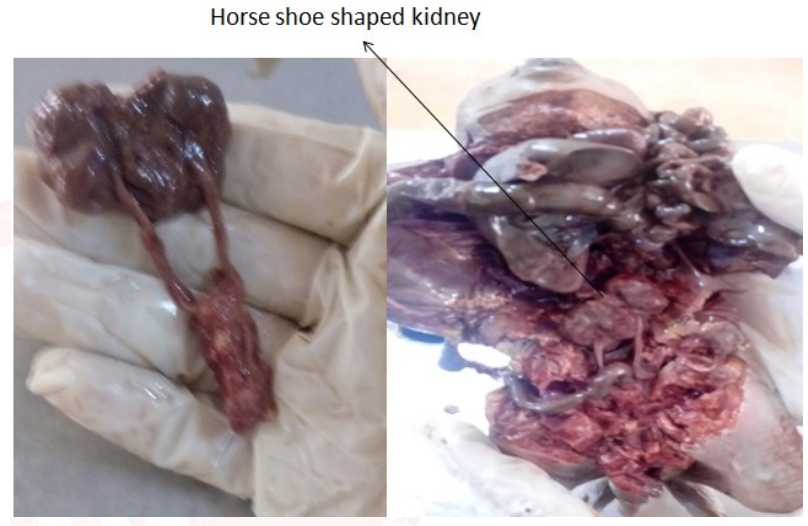

Fig. 7: Umbilical hernia.

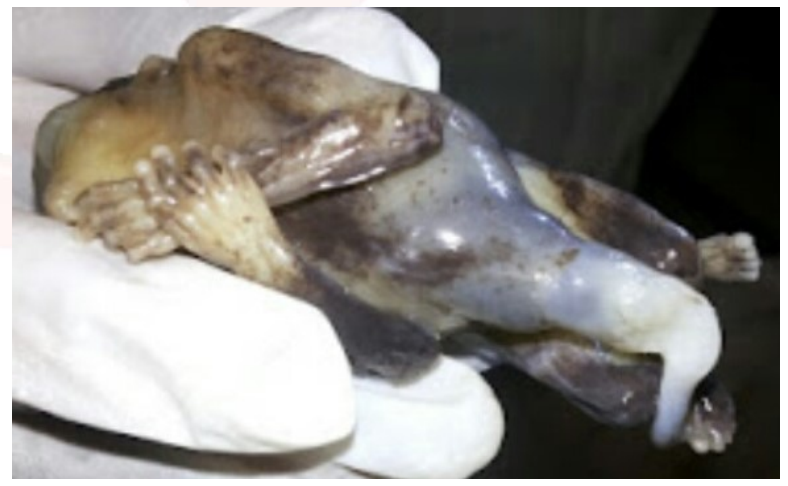

Fig. 8: Amniotic band syndrome.

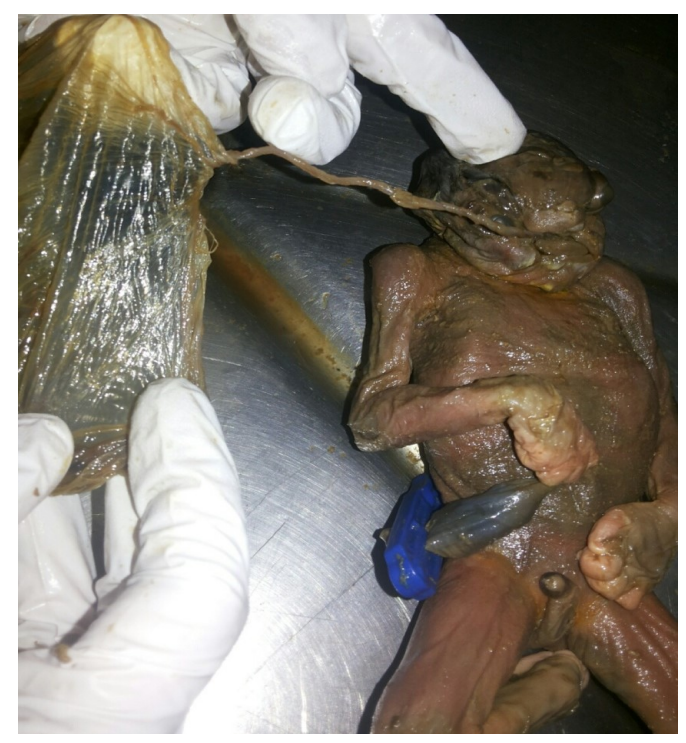


Fig. 9: Encepholocele.

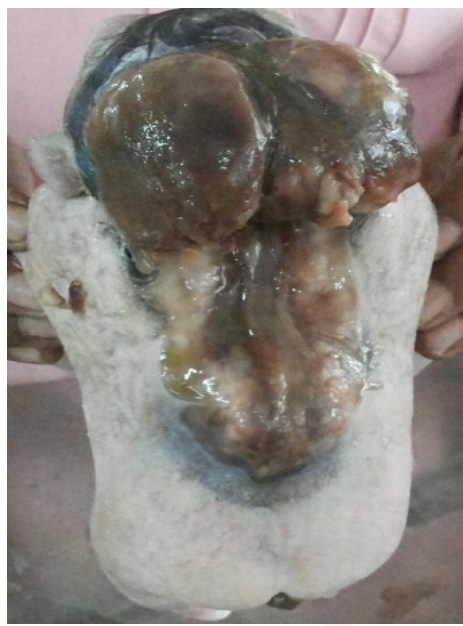

Fig. 10: Omphalocele.

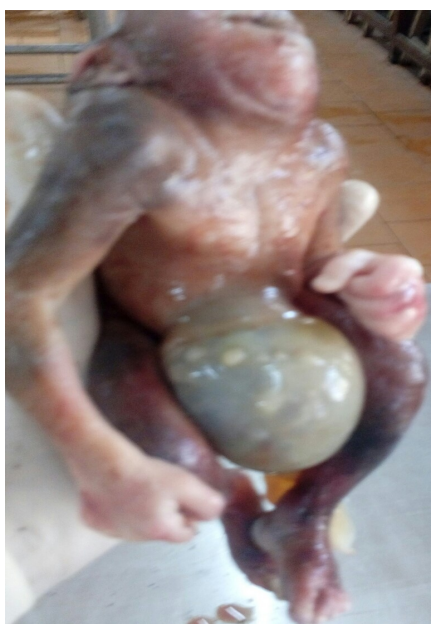

\section{DISCUSSION}

Table 5: Comparison of associated anomalies with Anencephaly.

\begin{tabular}{|c|c|c|c|c|c|c|}
\hline System & $\begin{array}{c}\text { Tan et al } \\
(\mathbf{1 9 8 4})[12]\end{array}$ & $\begin{array}{c}\text { Vare et al } \\
(\mathbf{1 9 7 1 )}[\mathbf{1 3}]\end{array}$ & $\begin{array}{c}\text { Neilson et al } \\
(\mathbf{2 0 0 6})[14]\end{array}$ & $\begin{array}{c}\text { Pandurang et al } \\
\text { (2012) [15] }\end{array}$ & $\begin{array}{c}\text { Singh et al } \\
\text { (2015) [16] }\end{array}$ & $\begin{array}{c}\text { Present } \\
\text { study (\%) }\end{array}$ \\
\hline Total incidences & 9.4 & - & 43 & 73 & 58 & 70 \\
\hline Head \& Neck & NAD & 7.5 & 14 & 2.5 & 13 & 15 \\
\hline CVS & 3 & 7.5 & 4.75 & 14.5 & 13 & 2.3 \\
\hline Respiratory system & 3 & NAD & NAD & 2.5 & 17.3 & 9.5 \\
\hline GIT & 29 & 32 & NAD & 14.5 & 13 & 4.7 \\
\hline Renal & 3 & 27 & 12 & NAD & 11.5 & 4.7 \\
\hline Musculoskeleton & 20 & 14.5 & 16.5 & 14.5 & 10.1 & 2.3 \\
\hline Genital & NAD & 5 & NAD & 12 & 1.4 & NAD \\
\hline Diaphragmatic hernia & NAD & 5 & 2.3 & 1 & 5.7 & NAD \\
\hline Umbilical hernia & 1 & NAD & NAD & NAD & NAD & 4.7 \\
\hline
\end{tabular}

Incidence of anencephaly is reported to be $1: 1000$ to $1: 20000$. In the present study the incidence of anencephaly in Victoria and Vani Vilas hospital was 1.04 in 1000 births.

In the present study 23 (38.4\%) were males \& $37(61.6 \%)$ were females. The majority were females in the present study, the literature also showed that anencephaly is more common in females $[7,8]$.

The rate of anencephaly could be higher in underdeveloped countries due to possible misdiagnosis, most probably due to poor diet; improper maternal health care, inappropriate treatment \& environmental factors also contribute to it [9]. The ratio of anencephaly is higher in Iranian population than compared to European population. It has been calculated that in Iranian population 13.1/10,000 newborns had anencephaly whose mothers aged $>35$ years $\&$ consanguineous marriage contributes $36 \%$ to anencephaly which was found to be similar in

present study [10].

Congenital anomalies vary in different studies. The study of malformation is greatly helpful in genetic counseling \& prenatal diagnosis in successive pregnancies [11]. Anomalies were found in 42 cases (70\%) in the present study \& it is compared with the other studies.

In present study, out of 42 cases, 25 females $(41.7 \%)$ \& 17 males $(28.3 \%)$ showed associated anomalies; majority of anomalies were in female anencephalic fetuses which was similar to some studies. Cleft lip \& palate were the most common defect $(14.3 \%) \& 19(45.3 \%)$ had spina bifida. There were no reproductive system anomalies in the present study.

Most of NTDs are associated with omphalocele, diaphragmatic hernia \& cleft lip. It was first described in 1981 by Czeizel \& named "schisis association (SA)" [17]. Polydactyly, conotruncal septation defects, limb abnormalities \& 
extremely rarely, oligodactyly were minor manifestations of SA $[17,18]$.

Another common association is amniotic band syndrome (ABS). ABS is a group of congenital anomalies that includes the extremities, cranio facial, vertebral regions \& body wall defects $[19,20]$.

Its pathogenesis includes germ disc disruption, genetic disruption, vascular disruption \& amniotic disruption [21]. We determined one case of ABS, amelia, omphalocele \& encephalocele in the present study.

Most of the organs in the present study were anatomically normal when it was compared with the control group \& some studies [22].

Literature showed that anencephalic fetuses were successful donors of hearts \& kidneys for transplantation [23].

The intake of $4 \mathrm{mg}$ per day of folic acid intake is recommended in mothers with history of neural tube defect $[23,24]$.

\section{CONCLUSION}

Present study concludes that since there is a chance of occurrence of anencephaly, $4 \mathrm{mg}$ of folic acid should be taken before 6 months of conceiving \& entire pregnancy.

Maternal factors, like age, alcohol consumption, smoking, febrile illness, consumption of certain drugs and chemicals, family history, season of birth, environmental factors, are risk factors of conceiving an anencephalic child and its associated anomalies; hence these factors should be avoided

Consanguineous marriages could be avoided and they could be told about the risks of the same in successive generations too.

All pregnant mothers have to go in for triple marker tests; that is, beta HCG, alphafetoprotein and estradiol.

Amniocentesis could be made compulsory for mothers with a history of an anencephalic child. The mother has to be counseled regarding the risks of another such fetus. The family has to be told about pedigree charts, incidence and occurrence of anencephaly in the population.

They should be told about the importance of consuming folic acid before and during pregnancy. Majority of organs were normal anatomically \& histologically, hence anencephalic fetal organs can be transplanted.

\section{Conflicts of Interests: None}

\section{REFERENCES}

[1]. Tica VI, Beghim M, Zaher M, Beghim E. Anencephaly: pitfalls in pregnancy outcome \& relevance of the prenatal exam. Rom J Morphol Embryol.2009;50:295-297.

[2]. Copp AJ, Brooks SA, Estibeiro JP, Shum AS, Cockcroft $\mathrm{DL}$, The embryonic development of mammalian neural tube defects. Prog neurobiol .1990;35:363-403.

[3]. Tonnil G, Azzonil D, Panteghinil M, Ventural A, Cavalli $P$, First trimester diagnosis of anencephaly associated with fetal malformation \& trisomy 18: report of a new cases \& gene analysis on folate metabolism in patients. Congenit Anom. 2007;47:101-104.

[4]. Gucciardi E, Pietrusiak MA, Reynolds DL, Rouleau J. Incidence of neural tube defects in Ontario. Canadian Med Assoc J 2002;167:237-240.

[5]. Merker B. Consciousness with a cerebral cortex: A challenge for neuroscience \& medicine. Behave Brain Sci .2007;30:63-81.

[6]. Patowary A. The Fourth Incision: A Cosmetic Autopsy Incision Technique. The American journal of forensic medicine and pathology. $2010 \mathrm{Mar}$ 1;31(1):37-41.

[7]. Gupta P, Nain P \& Singh J. Anencephaly: A Neural tube defects -A review, American journal of pharmtech research 2016;2(3).

[8]. Kheir AEM, Eisa WMH, Neural tube defects; clinical patterns, Associated risks factors \& maternal awareness in Khortoum state Sudan, Journal of medicine \& medical research 2015;3(1):1-6.

[9]. Mukhtiar Hassan, Niaz Muhammed, Farzana Gul, Sohail Ahmad, Frequency of Anencephaly in Hazara Division Of Pakistan, American Journal of Drug Delivery \& therapeutics 2015;2(1):039-043.

[10]. Golalipour M J, Najafi L, Keshtkar AA. Prevalence of anencephaly in Gorgan, northern Iran. Arch Iran Med. 2010;13:34-7.

[11]. Naik S, Venkataramanababu P, Study of various congenital anomalies in fetal \& neonatal autopsies, International Journal of Research in medical sciences May 2015;3(5):1114-1117.

[12]. Tan KC, Ratham SS, Kottegoda SR, Anencephaly: A retrospective analysis, Singapore 1976 to $1980 \mathrm{~J}$ of Med Genetics 1984;21;350-354.

[13]. Vare AM, Bansal PC. Anencephaly: An Anatomical study of 41 anencephalies Indian journal Pediatric 1971;38:301-305.

[14]. Neilson LAG, Maroun LL, Graem N, Neural tube defects \& associated anomalies in a fetal \&perinatal autopsy series, Acta patho Microbial Immunol scand 2006;114:239-246.

[15]. Panduranga C, Kangle R, Suranagi V, Pilli GS, Anencephaly: A pathological study of 41 cases J sci soc 2012;39:81-84. 
[16]. Singh J, Kapoor K, Kochhar S. Incidence of Anencephaly in a tertiary care hospital in North west India International journal of scientific \& research publications 2015;5(9):2230-315.

[17]. Czeizel A, Schisis- association. Am J Med Genet 1981;10:25-35.

[18]. Kutuk MS, Ozgun MT, Uludag S et al. A case of dichorionic twin pregnancy concordant for bilateral cleft lip 7 palate \& discordant for spinabifida; Schisis association. Fetal pediatr pathol 2013;32:371-4.

[19]. Kulkarni M L, Gopal PV, Amniotic band syndrome, Indian Pediatric 1990;27:471-6.

[20]. Chen H, Gonzalez E, Amniotic band sequence \& its neurocutaneous manifestations. Am J Med Genet 1987;28:661-73.
[21]. Miller ME, Graham Jr JM, Higginbottom MC, Smith DW. Compression- related defects from early amnion rupture; evidence for mechanical teratogenesis. J Pediatric 1981;98:292-7.

[22]. Potter's pathology of the fetus, infant and child. vol $1 \& 2$, second edition, Elsevier

[23]. Gupta P, Nain P \& Singh J. Anencephaly:A Neural tube defects -A review, American journal of pharmtech research, 2016;2(3).

[24]. Moore L, Anencephaly, Journal of Diagnostic Medical Sonography 2010;26(6):286-289.

\author{
How to cite this article: \\ Shilpa K, Priya Ranganath, Sumathi S. FREQUENCY OF \\ ANENCEPHALY AND ITS ASSOCIATED ANOMALIES. Int J Anat Res \\ 2018;6(2.3):5294-5300. DOI: 10.16965/ijar.2018.190
}

